\title{
PARQUE GENERAL SAN MARTÍN: Imagen y memoria de su transformación ${ }^{(1)}$
}

\author{
EUGENIA VIDELA ${ }^{(2)}$
}

El Parque General San Martín (denominado originalmente Parque Público del Oeste, 1896) es el parque más antiguo e importante de la ciudad de Mendoza, capital de la provincia homónima, de la República Argentina. Abarca 307 ha cultivadas y 86 ha en expansión, con $17 \mathrm{~km}$ de recorrido.

Orgullo de los mendocinos, el parque tiene un gran valor como objeto cultural, por las múltiples significaciones que ha adquirido y acumulado desde su génesis. Actualmente, es el pulmón verde de la ciudad y el paseo más popular de habitantes y turistas.

Desde sus orígenes -reflejo del pensamiento eurocéntrico de la élite dirigente - ha sufrido procesos de transformación acordes a los criterios del momento (luchas políticas, costumbres, modas). Al estar animado por lo social, el parque cobra vida y se manifiesta como testimonio vivo del permanente esfuerzo y la tenacidad del mendocino en su modo de habitar el desierto.

En esta ponencia reflexionaremos sobre los valores del sitio, su significado, su sentido y su participación en el imaginario colectivo, como ámbito simbólico de identidad regional.

\section{Contexto geográfico}

La provincia de Mendoza se ubica en el centro-oeste de la Argentina, al pie de la Cordillera de los Andes. Se caracteriza por un clima desértico con alta insolación, baja humedad relativa, precipitaciones torrenciales, alrededor de 200 milímetros anuales, distribuidas en unas pocas lluvias de verano. La vegetación natural característica es la estepa arbustiva.

En este entorno se ha desarrollado una cultura de oasis por el aprovechamiento del agua de los ríos y el complemento de aguas subterráneas. El trabajo de los mendocinos ha generado importantes áreas irrigadas que hoy representan el 3\% de la superficie provincial. En estos oasis asientan los principales núcleos urbanos que concentran más del 90\% de la población. El Oasis Norte incluye el Área Metropolitana de Mendoza, conglomerado urbano más importante del oeste árido argentino.

\section{Surgimiento del Parque del Oeste}

La Mendoza fundada a mediados del siglo XVI sufrió un desbastador terremoto en 1861. Se trazó entonces una Nueva Ciudad, adyacente al sudoeste de la antigua, aplicando el damero colonial pero incorporando los conceptos modernos de la época. Una gran plaza-parque en el centro y cuatro plazas menores en sus diagonales, con calles anchas y avenidas, con acequias de riego - como parte de su infraestructura- que permitieron la implantación de árboles en las calles y en las plazas. En tanto, la vieja ciudad destruida se regenera a partir de la antigua traza, conformando la nueva y la vieja ciudad realidades diferentes destinadas a recibir los adelantos del "progreso". Hacia fines del siglo XIX (lámina 1), el casco urbano terminaba en las vías férreas, hacia el oeste había fincas y quintas hasta el canal Jarillal construido en el siglo anterior (Ponte, 1999), más allá el piedemonte semidesértico de la precordillera mendocina.

Por aquel entonces, el ambiente urbano en Mendoza era altamente insalubre. El Censo Nacional de 1895 y el Informe Coni de 1896 expresaron la gravedad del estado sanitario de la ciudad, de su análisis surgió una serie de políticas de saneamiento (CIRVINI, 1992).

La historia atribuye el origen del Parque a la intención de la clase política de sanear la ciudad. Para la prensa oficial, el proyecto era de utilidad "tanto en el sentido de la higiene como del ornato". Según dichos del diario La Nación de mayo 1897: “...El gobierno de Mendoza es acreedor a aplausos por las medidas que está poniendo en práctica para favorecer el desarrollo de las plantaciones de árboles, fuente de perpetua belleza y agentes de salud y riquezas. Dentro de este plan, la idea del parque en vías de construcción es un feliz complemento que dotará a la linda ciudad andina, de un magnífico atractivo agregado a los muchos que la hacen sitio preferente de turistas y veraneantes" (SOSA, 1964).

Sin embargo, en vista de las reales necesidades sanitarias, la prioridad fijada para la construcción de un parque artificial de casi 400 hectáreas era señalada desde la prensa opositora como un desatino y una "frivolidad", dentro de los planes megalómanos del poder político (CIRVINI, 1996).

Más allá de las críticas de la oposición, la obra más ambiciosa y representativa de la cultura hegemónica finisecular, muy ligada a la visión que tenía de sí misma la clase dirigente (CIRVINI, 1992), comenzó su ejecución mientras otras propuestas para el saneamiento de la ciudad siguieron postergadas durante décadas.

\section{El proyecto original}

El proyecto fue encomendado al paisajista francés Jules Charles Thays, por entonces Director de Paseos de la Ciudad de Buenos Aires. El plano que el paisajista presentó -a modo de plan maestro- está fechado en Buenos Aires el 11 de noviembre de 1896.

El trazado original abarcaba una superficie triangular cuyos límites eran: la Avenida de Los Andes, por el norte; el canal Jarillal, por el sur y, cerrando el triángulo por el oeste, el canal del Estado expresamente realizado para el riego del parque (lámina 2). El plano comprendía 329 hectáreas en parque y 70 repartidas en 80 lotes que iban a

\footnotetext{
(1) Recebido em 10 de maio de 2013 e aceito para publicação em 30 junho de 2013.

(2) Professora, Universidad Nacional de Cuyo- Facultad de Ciencias Agrarias - Mendonza, Argentina
} 
ser ofrecidos a la venta de particulares.

Aparentemente, la información que disponía Thays al momento de proyectar fue muy poca: sabía que era un terreno inculto y árido en el pedregal del piedemonte, que distaba casi dos kilómetros del centro de la ciudad y estaba a ocho cuadras de las vías del ferrocarril; entre las vías y el futuro parque se desarrollaba un área agrícola cultivada (CIRVINI, 1996).

Thays eligió como ingreso el eje este-oeste de la Ciudad Nueva que conectaba con la plaza central, vía concebida a modo de la perspectiva clásica del jardín francés, jerarquizado por la simetría en la vegetación. Propuso un camino de cintura, articulado a dos rotondas sobre la avenida que vincula al parque con la ciudad (Avenida de los Andes), una tercera central y una cuarta en el extremo sur. En la trama circulatoria interior hizo uso de la línea curva y la asimetría, características del jardín pintoresquista inglés. También la distribución de prados y masas de árboles corresponde a este estilo.

El diseño original proponía pabellón restaurant, kiosco de música, zona de cricket y lawn tennis, velódromo, zona para práctica de foot-ball, jardín botánico, jardín zoológico, zonas de servicios (baños, criadero de plantas, caballerizas, filtros), lagos y embarcaderos, hipódromo con sus correspondientes tribunas, boletería y confitería, grutas, miradores, cascadas, casa de guardianes, entre otras.

El proyecto respondía a los tres principios centrales que explicaban la necesidad de la creación de parques públicos: la higiene, la recreación y la estética (Cirvini, 1996). Fue llevado a la práctica con algunas modificaciones: reducción de tamaño y variantes de trazado y uso que tendieron a simplificarlo, no se materializaron las quintas particulares ni gran parte del equipamiento de "sports".

La concreción y sus transformaciones. Cronología

A poco de presentado, comenzó la ejecución del ambicioso proyecto. A través de los años, con las sucesivas intervenciones o ampliaciones se fueron incorporando nuevos espacios que permitieron actividades no propuestas en el plan original.

La implantación conllevó ingentes esfuerzos: "Más de 40.000 árboles se disponían al final del primer año de tareas... El riego debe cumplirse con carros municipales, distribuyendo el agua con baldes, planta por planta" (DIARIO LOS ANDES, 1982).

El unitario proyecto de Thays quedó fracturado por la presencia de un curso de agua temporario no tenido en cuenta en el proyecto original: en la fracción sur sólo el hipódromo mantuvo el emplazamiento; en la norte se concretó el parque propiamente dicho, constituido como el paseo público que ha llegado hasta nuestros días (PONTE, 1999).

El Parque ya en 1909 era una realidad. "Calles de trazado sinuoso, dan acceso a todos los puntos del parque. Una amplia avenida bordea la parte central donde se encuentra un gran lago para regatas, con una isla en el medio. También existe una explanada con quiosco para orquesta, un vivero y un pequeño jardín zoológico. El conjunto se irriga con un sistema de canales para riego y para la alimentación del lago" (Ponte, 1999). A la usanza de los parques europeos, cuyo modelo fue referencia para el diseño, el Parque del Oeste incorporó unos elegantes portones de hierro, con farolas que iluminaban el acceso (PONTE, 1999).

Hacia 1910, se le otorgó una utilidad recreativa a la instalación ferroviaria que sirvió para la excavación del lago. Los volquetes de extracción fueron remplazados por tres o cuatro vagones de pasajeros con un recorrido hasta el antiguo zoológico que luego se extendió a otros sectores del parque. El trencito del Parque funcionó hasta 1923.

Gradualmente, entre los años 1910 y 1914, se incorporó el resto del equipamiento escultórico: algunos elementos monumentales en los puntos nodales de la trama (CIRVINI, 1996), otros de menor escala en calles internas y en paseos peatonales.

En 1914 se produjo la primera expansión significativa hacia el oeste, con la inauguración del Monumento al Ejército de los Andes, en el Cerro del Pilar -actual Cerro de la Gloria-, obra del escultor uruguayo Juan Ferrari (CIRVINI, 1996). Una obra complementaria, de fundamental importancia, fue la que permitió dotar de agua al cerro para posibilitar su forestación. Un sistema de acequias que recorre escalonadamente ambas laderas, permite regar toda la vegetación existente.

Entre 1919 y 1924 se construyó la Rosaleda -paseo peatonal de jardinería a la moda francesa- en la margen este del Lago. Se trata de un "jardín de rosas", con un trazado regular y geométrico, equipado con pérgolas, bancos y esculturas (CIRVINI, 1996). En predios del Parque Sud, (así llamado el parque al sur del zanjón que dividíó el parque), se construyó el hipódromo, el Hospital de Infecciosos y sus correspondientes áreas forestadas. Se otorgaron las cesiones a dos clubes que introdujeron la práctica del fútbol: Gimnasia y Esgrima e Independiente Rivadavia.

En 1933, con el objeto de valorar las plantas existentes en el Camino del Inca y la protección de especies de los Andes áridos se destinan nueve hectáreas del parque para la creación del llamado "Parque Aborigen". En 1936, se instala el Observatorio Meteorológico Nacional, con cesión de esos terrenos a la nación. En 1937, a orillas del lago, queda inaugurado un "balneario moderno para uso público, de arquitectura racionalista" (DIARIO LOS ANDES, 1982), que incluía confitería, llamado "Playas Serranas".

Hacia 1940 fue aprobado el "Plan regulador de mejoras del Parque" que constituyó la más importante refacción y remodelación del parque desde su creación (CIRVINI, 1992). Las obras más significativas fueron: traslado del jardín zoológico (1938) a la ladera este del Cerro de la Gloria, construcción del Gran Teatro Griego y del Pequeño Teatro, reformas al entorno y pie del Monumento Ejército de los Andes, eliminación de cercos y alambrado perimetral, reformas en el ingreso del parque (inmediaciones de los portones y levantamiento de la balaustrada), parquización de los terrenos del antiguo zoo y de nuevas áreas anexadas, obras de infraestructura para riego. Uno de los méritos más significativos que tuvo esta intervención fue el acertado criterio paisajístico del proyectista, quien al reforestar áreas del trazado antiguo o forestar las expansiones lo hizo con una lógica de integración y respeto hacia lo existente (CIRVINI, 1996).

En 1947, con motivo del natalicio de San Martín, se dispuso oficialmente dar al Parque del Oeste, sus dependencias y terrenos anexos el nombre de Parque 
General San Martín.

Por aquellos tiempos, la Universidad Nacional de Cuyo recibió la cesión de tierras para construir la Ciudad Universitaria. Proyecto que demandó décadas para su concreción.

En la década del 70, se realizó la construcción del estadio para el mundial de fútbol de 1978, al pie del Cerro de la Gloria en la denominada “olla” del antiguo autódromo. Esta obra significó la desaparición del Parque Aborigen. Por ese entonces, se inauguran las instalaciones del Centro Regional de Investigaciones Científicas y Tecnológicas (CRICYT).

En ocasión de festejarse el centenario del parque (1996/97) se decidió renovar la alameda de la Avenida del Libertador. Además de reemplazar los vetustos álamos, se propuso una solución técnica muy imaginativa a la fuerte pendiente oeste-este de las acequias que flanquean dicha avenida. Solución impecable tanto desde el punto de vista técnico como visual: las acequias revestidas en piedra -responde a la imagen tradicional de la acequia mendocina-, la base escalonada con piedras sueltas mejora la permeabilidad frente a los árboles, detiene la velocidad de agua y crea remansos para una mejor infiltración.

La restauración de monumentos y estatuaria, y la ampliación de las zonas parquizadas en el sector sur-oeste del parque se cuentan entre las últimas intervenciones en el año 2006.

\section{La apropiación del parque. La dimensión social}

La función social de las áreas verdes está vinculada a la evolución de los hábitos de la población y de la conducta ciudadana respecto al espacio público. Los condicionantes socio-económicos, culturales y políticos han ejercido un papel decisivo sobre la materialización y los valores del paisaje urbano. Por ello, no podemos dejar de analizar la función social del Parque desde una perspectiva histórica.

El Parque del Oeste, obra que formó parte del gesto civilizador que caracterizó a los personajes de la generación del '80, significó la domesticación racional de la aridez mendocina, oponiendo al desierto un ordenado bosque artificial (RAFFA, 2011).

La propuesta estuvo consustanciada por lo pintoresco y por el exotismo con la idea de acercar la vida provinciana al cosmopolitismo, en el marco de orden y progreso que imponía la modernidad de fines del siglo XIX (PONTE, 1999). Esa Mendoza moderna, comandada por agentes liberales del campo político y proyectada por la elite como espacio propio, tenía sus espacios públicos vedados al uso popular (RAFFA, 2011). Si bien surgió como parque "público", nació y permaneció durante largo tiempo como ámbito exclusivo para la recreación y uso de selectos sectores sociales.

HACIA 1910 el paseo estaba prácticamente concluido para deleite de la alta sociedad que repetía el ritual del encuentro social en los quioscos de música. Desde sus comienzos se trató de un paseo aristocrático, aunque era público, había sido construido a partir del presupuesto provincial (RAFFA, 2011) y no existía una prohibición explícita para que los sectores populares lo usaran. Otras circunstancias acentuaron el carácter selectivo: la carencia de equipamiento a escala peatonal hicieron habitual el paseo en carruaje y la ausencia de transporte público hacía muy difícil a la mayoría de los pobladores acceder al paseo puesto que las distancias a cubrir eran importantes.

A medida que avanzó la segunda década del siglo XX, con el cambio de gobierno, el uso del espacio público en Mendoza comenzó a generalizarse (RAFFA, 2011), las plazas y parques creados por y para la elite comenzaron a cambiar su ambiente. A través de actos de fuerte carga simbólica, los distintos espacios urbanos se ocuparon masivamente.

La creación del Rosedal, adecuada al uso popular, en cuanto era un paseo peatonal, la prolongación de la línea de tranvías eléctricos (transporte público) que desde 1925 permitían llegar fácilmente a los portones del parque, junto con la aparición de los clubes de fútbol tendieron a neutralizar el carácter elitista del paseo (CIRVINI, 1996). Con los actos cívicos realizados para las fechas patrias, los festejos de Carnaval y posteriormente la realización de la tradicional Fiesta de la Vendimia, el Parque fue paulatinamente democratizado y se constituyó en parte del imaginario colectivo.

La gradual apropiación del parque por parte de los sectores medios y populares prosperó con la construcción del balneario popular de Playas Serranas, en el extremo sur del lago (CIRVINI, 1996). Las importantes remodelaciones a nivel estético y funcional llevadas a cabo a partir de 1940 generaron una vinculación más directa con la ciudad y con el uso público. Estas reformas tendieron, en general, a satisfacer nuevas necesidades sociales y a posibilitar nuevas prácticas, de modo de incorporar el parque a la cultura de masas (CIRVINI, 1996). A diferencia de los períodos anteriores el diseño de los espacios verdes estaba orientado hacia lo social, ya no enfocado hacia la elite mendocina, sino más bien al conjunto de la sociedad.

El Parque ha llegado hasta nuestros días como el lugar más importante de recreación y esparcimiento de la ciudad y consolida el acceso de la ciudadanía a la naturaleza como un derecho social. Es el "paseo de los mendocinos" donde se desarrollan distintas actividades culturales, recreativas y deportivas. Hito para el turista que lo recorre y elogia, quien entonces comprende y se sorprende de la voluntad del mendocino en su lucha contra la aridez.

El Parque escenario de paisajes efímeros

Dentro de los complejos significados histórico-culturales que el Parque asume debemos destacar dos hechos muy significativos como parte del patrimonio intangible y su relación con la construcción de los imaginarios sociales: los festejos vendimiales que desde del año 1936, año tras año, han erigido su escenografía en distintos ámbitos del parque y los pabellones de la "Feria de América", exposición que promovió la industria y el comercio del continente durante los primeros meses de 1954.

La Fiesta de la Vendimia es el festejo más popular y representativo de los mendocinos. Espacio convocante y reproductor de símbolos y representaciones de la provincia de Mendoza, exalta la uva, el vino y sus hacedores. Los escenarios de los espectáculos centrales de las primeras fiestas se montaron en la rotonda del parque. Aumentada la escala y cada vez con mayor convocatoria, a partir del año 1950, el acto central de la fiesta se desarrolló en una depresión natural (ex autódromo, hoy Estadio Malvinas 
Argentinas). Finalmente, desde 1963, el Teatro Griego Frank Romero Day es el lugar del encuentro anual, donde tanto el público del recinto como el ubicado en "los cerros" participan de un espectáculo de luz, color y sonido sin igual.

La Feria de América, articulada alrededor del lago, incluyó pabellones de distintos países de América y de provincias de Argentina, fue concebida como un gran espectáculo donde el producto industrial argentino y americano desempeñó el papel protagónico. Reflejo de las nociones de modernidad y progreso, en términos de avance industrial, y de vanguardia al momento de pensar en el arte, la arquitectura y el diseño (QUIROGA, 2012), significó una gran atracción para los habitantes de la región y los visitantes... quizás una de las bases para la conformación de la primera escuela de diseño del país.

\section{La mirada estético-paisajística}

"Este espacio tan característico de Mendoza, es un oasis pleno de todos aquellos elementos tan preciados por el hombre de desierto: sombra, agua y vegetación" (PALADINI y ROBELLO, 1995). El Parque San Martín, por sus dimensiones, diseño y profusión vegetal, constituye uno de los ejes fundamentales del patrimonio paisajístico mendocino.

Las avenidas principales de $20 \mathrm{~m}$ de calzada, con amplios caminos peatonales en ambos lados, están enmarcadas por alineaciones de árboles de una misma especie que en muchos casos dan nombre a la calle (avenida de los plátanos, de las palmeras, de las tipas).

Abundan los prados cubiertos por césped espontáneo regados "a manto", donde se distribuyen agrupamientos de árboles y arbustos, con alta proporción de especies exóticas. Éstos conforman masas de una misma o de distintas especies, que a veces involucran a las callejuelas que conectan las grandes avenidas. El bosque se estructura con árboles que destacan por su gran altura y follaje persistente. Los bosquetes, agrupación más extendida y baja, con árboles de menor magnitud y follaje caduco. El sotobosque, hoy continuo y tupido por la dispersión de las especies que lo conforman. Como figura destacada, en algunos prados, aparecen vegetales únicos con valor escultórico.

En los sectores de uso peatonal -alrededor del lago, el rosedal, el ingreso por los portones- la vegetación es más variada, de tipo jardineril, adecuada en escala y ornamento.

Al recorrer el Parque, la primera valoración perceptual es la visual. El trazado curvilíneo de las calles, el ritmo de forestales en alineación, los macizos de árboles que con el tiempo han adquirido un "aire de espontáneo", el dinamismo de llenos y vacíos, el juego de luces y sombras al caminarlo, estimulan el placer de los sentidos, la necesidad de goce y contemplación. El contacto con la naturaleza, las sensaciones de relax y tranquilidad trascienden el marco estético y apuntan, en definitiva, a una mejor calidad de vida.

\section{Valor Ecológico-Ambiental}

La manera de mirar el paisaje que corresponde a nuestro tiempo, obliga a identificar el componente natural como base para la construcción del territorio, por ello es imprescindible la valoración ambiental.
El aporte de la biomasa vegetal se traduce en una mejora tangible de la calidad ambiental (calidad del aire, moderación de la temperatura) y estética de la ciudad y su entorno. Asimismo, es un elemento clave para la conservación de la biodiversidad, como alimento y refugio de la fauna, y un magnífico recurso de cara a la educación ambiental y a la formación de una conciencia ecológica en la ciudadanía. Basado en estos principios, en 1996, el Parque considerado "una unidad ambiental con calificada representatividad como patrimonio natural-cultural" fue declarado Área Ambiental Urbana Protegida.

La calidad de un espacio urbano puede expresarse a través de diferentes parámetros, tales como, porcentaje de $\mathrm{m}^{2}$ de espacios verdes por superficie de ciudad, o $\mathrm{m} 2$ de espacios verdes por habitante, éstos plantean relaciones cuantitativas donde sólo se considera la superficie involucrada sin calificar el tipo de espacio verde desde el punto de vista de sus elementos constitutivos, proporciones y su influencia ambiental relativa.

Actualmente, la Cátedra de Espacios Verdes de la Facultad de Ciencias Agrarias (UNCuyo) ha determinado que es posible caracterizar ambientalmente la influencia de los espacios verdes urbanos, aún en etapa de proyecto, a partir del análisis del comportamiento termodinámico de los diferentes tipos de superficie, a través del balance calórico (CARRIERI et al., 2009). Considera el valor ambiental de la localidad, entendido como la capacidad de modificar favorablemente el confort de un lugar y su entorno, expresado como índice ambiental (IA). Este índice que en el entorno natural de Mendoza (piedemonte, con vegetación arbustiva) es igual a 0,25 , se eleva a 0,40 en la ciudad (el índice mejora respecto al paisaje natural debido a que se trata de una ciudad con calles arboladas). El índice es igual a 0,74 en el Parque lo que demuestra la alta confortabilidad de este espacio que incide de forma notable aún en zonas aledañas (zona más cara de la ciudad de Mendoza, en cuanto a su valor inmobiliario).

\section{REFLEXIÓN FINAL}

El Parque General San Martín producto de la interacción del habitante y su ambiente, único proceso capaz de brindar legitimación social a la representación construida del paisaje cultural, integra pasado y futuro en un presente complejo y dinámico.

Aquella construcción colectiva -utopía de sus gestores, tesón de sus hacedores y esmero de quienes lo embellecieron y mantuvieron-, qué mas que un merecido homenaje a quienes supieron "hacer las cosas bien" para el disfrute hoy de mendocinos y visitantes.

\section{BIBLIOGRAFÍA}

CIRVINI, S. El Parque General San Martín (antiguo Parque del Oeste), Mendoza. En Sonia Berjman (comp.), Tiempos de los parques. Buenos Aires, Instituto de Arte Americano e Investigaciones Estéticas, Facultad de Arquitectura y Urbanismo UBA. 1992, p. 28-31.

CIRVINI, S. A. El Parque del Oeste. De paseo aristocrático a parque popular. En: Ministerio de Ambiente y Obras 
Públicas de la Provincia de Mendoza. Centenario del Parque General San Martín 1896-1996. Tomo 1. Mendoza, Zeta Editores, 1996. v. 1, p. 51-70.

CARRIERI, S.A. et al. Propuesta de metodología para la calificación bio-ambiental de espacios verdes mediante coeficientes ecofisiológicos. Revista de la Facultad de Ciencias Agrarias. UNCuyo, v. 41, n. 1, p. 1: 1-21, 2009.

Diario Los Andes. Cien años de vida mendocina.1882-1982. Mendoza, Edición extraordinaria, 1982, 205 p.

PALlADINI, E., ROBELlO, P. Árboles y arbustos del Parque General San Martín. Mendoza, Ediciones Culturales Mendoza, 1995. 217 p.
PONTE, J.R. La fragilidad de la memoria. Representaciones, prensa y poder de una ciudad latinoamericana en tiempos del modernismo. Mendoza, 1885/1910. Mendoza, Ediciones Fundación CRICYT, 1999, 452 p.

QUIROGA, W.(ed.). Feria de America: Vanguardia invisible. Mendoza, Fundación del Interior, 2012, 345 p.

RAFFA, C. 2011. El espacio público como lugar de legitimación política: sobre las disputas entre Emilio Civit y José Lencinas, Mendoza 1910 y 1918. Prohistoria (online) vol.15 pp. 00-00. 2011.

SOSA, J. Parque General San Martín. Mendoza, Edición Oficial, adhesión del Gobierno de Mendoza al Sesquicentenerio de la Independencia Argentina. 1964, 180 p. 